\title{
Maternal supplementation with rumen-protected methionine increases prepartal plasma methionine concentration and alters hepatic mRNA abundance of 1-carbon, methionine, and transsulfuration pathways in neonatal Holstein calves
}

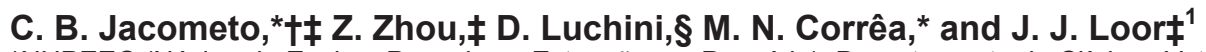 \\ *NUPEEC (Núcleo de Ensino, Pesquisa e Extensão em Pecuária), Departamento de Clínicas Veterinária, \\ Programa de Pós-Graduação em Biotecnologia, Universidade Federal de Pelotas, 96010-900, Pelotas, RS, Brazil \\ †Programa de Zootecnia, Facultad de Ciencias Agropecuarias, Universidad de La Salle, 110231, Bogotá D.C., Colombia \\ $\ddagger$ Mammalian NutriPhysioGenomics, Department of Animal Sciences and Division of Nutritional Sciences, University of Illinois, Urbana 61801 \\ §Adisseo NA, Alpharetta, GA 30022
}

\section{ABSTRACT}

An important mechanism of nutritional "programming" induced by supplementation with methyl donors during pregnancy is the alteration of mRNA abundance in the offspring. We investigated the effects of rumenprotected Met (RPM) on abundance of 17 genes in the 1-carbon, Met, and transsulfuration pathways in calf liver from cows fed the same basal diet without (control, CON) or with RPM at $0.08 \%$ of diet dry matter/d (MET) from -21 through $+30 \mathrm{~d}$ around calving. Biopsies ( $\mathrm{n}=8$ calves per diet) were harvested on d 4, 14, 28, and 50 of age. Cows fed RPM had greater plasma concentration of Met $(17.8$ vs. $28.2 \mu M)$ at -10 $\mathrm{d}$ from calving. However, no difference was present in colostrum yield and free AA concentrations. Greater abundance on d 4 and 14 of betaine-homocysteine Smethyltransferase 2 (BHMT2), adenosylhomocysteinase $(A H C Y$; also known as $S A H H)$, and cystathionine$\beta$-synthase $(C B S)$ in MET calves indicated alterations in Met, choline, and homocysteine metabolism. Those data agree with the greater abundance of methionine adenosyltransferase 1A (MAT1A) in MET calves. Along with $C B S$, the greater abundance of glutamate-cysteine ligase $(G C L C)$ and glutathione reductase $(G S R)$ on d 4 in MET calves indicated a short-term postnatal alteration in the use of homocysteine for taurine and glutathione synthesis (both are potent intracellular antioxidants). The striking 7 -fold upregulation at d 50 versus 4 of cysteine sulfinic acid decarboxylase $(C S A D)$, catalyzing the last step of taurine synthesis, in MET and CON calves underscores an important role of taurine during postnatal calf growth. The unique role of taurine in the young calf is further supported

Received June 24, 2016.

Accepted December 8, 2016.

${ }^{1}$ Corresponding author: jloor@illinois.edu by the upregulation of $C B S, G C L C$, and $G S R$ at d 50 versus 14 and 28 in MET and CON. Although betainehomocysteine S-methyltransferase (BHMT) activity did not differ in MET and CON, it increased $\sim 50 \%$ at d 14 and 28 versus 4 . A significant positive correlation $(\mathrm{r}=0.79)$ was present between $B H M T$ abundance and BHMT activity regardless of treatment. The gradual upregulation over time of BHMT2 and $S A H H$ coupled with the gradual upregulation of MAT1A and the DNA (cytosine-5-)-methyltransferases (DNMT1, DNMT3A, DNMT3B) in MET and CON calves was indicative of adaptations potentially driven by differences in intake of milk replacer and starter feed as calves grew. In that context, the $\sim 2.5$-fold increase in abundance of $D N$ MT3B at d 50 versus 4 in MET and CON indicate that DNA methylation might be an important component of the physiologic adaptations of calf liver. The data indicate that calves from MET-supplemented cows underwent alterations in Met, choline, and homocysteine metabolism partly to synthesize taurine and glutathione, which would be advantageous for controlling metabolic-related stress. Whether the effects in MET calves were directly related to increased Met supply in utero remains to be determined.

Key words: calf gene expression, methionine cycle, methyl donors, 1-carbon metabolism

\section{INTRODUCTION}

Among the several environmental factors that can affect fetal development, maternal diet composition and nutrient supply are major players, and can elicit longlasting effects on animal productive life (Symonds et al., 2010; Wu et al., 2004). Nutritional "programming" due to changes in the intake of micronutrients (e.g., folate, vitamins, and EAA, both pre- and postnatally) has been linked to alterations in mRNA abundance (Chmurzynska, 2010). Methionine is an indispensable 
AA that animal tissues can obtain from feed intake, protein breakdown, and re-synthesis from homocysteine in the Met cycle. From a cellular standpoint, Met is essential for protein, antioxidant (taurine and glutathione), and S-adenosylmethionine (SAM) synthesis (Bertolo and McBreairty, 2013). Synthesis of SAM via the 1-carbon and Met metabolism cycles provides methyl groups required for various cellular functions including synthesis of phosphatidylcholine (PC) and DNA methylation that can alter gene transcription. Research with nonruminants provided evidence that essential nutrients in the maternal diet such as Met, folate, betaine, and choline, elicit epigenetic changes regulating gene transcription in the offspring that can have long-term consequences in health and metabolism (O'Neill et al., 2014).

From a practical standpoint, EAA nutrition in dairy cows has become a key aspect of diet formulation as a way to reduce dietary $\mathrm{CP}$, increase efficiency of $\mathrm{N}$ use, and improve EAA profiles in the MP that can be used by tissues (Sinclair et al., 2014). The focus has been on Met and Lys, both of which are well known to be first and second limiting for milk synthesis (NRC, 2001). Besides its role in milk protein synthesis, the fact that Met concentration in plasma decreases markedly few weeks before parturition (Zhou et al., 2016) also underscores the potential limitations in availability for the growing fetus. A classic study demonstrated the essentiality of Met for normal embryo development (Coelho et al., 1989); embryos cultured in medium containing serum from cows supplemented with rumen-protected Met (RPM), which increased cow serum Met from 4.8 to $\sim 75 \mu \mathrm{g} / \mathrm{mL}$ after $14 \mathrm{~d}$ of supplementation, developed normally in vitro compared with embryos cultured in cows not receiving supplemental RPM (see Table 6 in Coelho et al., 1989).

To our knowledge, no studies are available dealing with supplementation of methyl donors to dairy cows during the dry period that have evaluated residual effects on the transcription of genes related to methyl donor metabolism in the calf liver. Therefore, the specific objective of this study was to profile the abundance of 17 genes in the 1-carbon and Met metabolism cycles as well as the activity of betaine-homocysteine S-methyltransferase (BHMT) in liver tissue of calves born to cows supplemented with Met during the last 21 d of pregnancy (Jacometo et al., 2016). Data on transcription of metabolic genes have been reported elsewhere (Jacometo et al., 2016).

\section{MATERIALS AND METHODS}

All the procedures for this study were conducted in accordance with a protocol approved by the Institu- tional Animal Care and Use Committee of the University of Illinois (protocol \#13023).

\section{Maternal Treatments}

Details of the experimental design have been published previously (Jacometo et al., 2016). Briefly, 40 multiparous Holstein cows received a common earlydry period diet ("far-off diet") from -50 to $-25 \mathrm{~d}$ relative to parturition, with low energy and high straw designed to meet and not greatly exceed $100 \%$ of energy requirements. Cows received a higher-energy diet from $-21 \mathrm{~d}$ until $+30 \mathrm{~d}$ after calving (Supplemental Table S1; https://doi.org/10.3168/jds.2016-11656). Calves were born to cows randomly assigned to receive RPM (MET, n = 20; Smartamine, Adisseo NA, Alpharetta, GA) at $0.08 \%$ of diet DM/d Met ( 2.9:1 Lys:Met) or no supplemental Met $(\mathbf{C O N}, \mathrm{n}=20, \sim 3.35: 1$ Lys:Met). The Met supplement was top-dressed on the TMR. The RPM supplement provided an additional $10 \mathrm{~g}$ per $\mathrm{d}$ of Met in the MP. Ingredient and chemical composition of the diets is reported in Jacometo et al. (2016). Cow BW $(773 \pm 11 \mathrm{~kg})$ and BCS $(3.51 \pm 0.05)$ throughout the experiment did not differ. After birth, calves were fed a common diet and managed similarly. Blood samples (coccygeal vein) for plasma isolation were collected into evacuated tubes (BD Vacutainer, BD and Co., Franklin Lakes, NJ) containing lithium heparin at $-10 \mathrm{~d}$ relative to calving. Concentrations of free AA were analyzed at the University of Missouri Agricultural Experiment Station Chemical Laboratories (Columbia) by cationexchange chromatography coupled with postcolumn ninhydrin derivatization and quantification.

\section{Animal Management and Calf Enrollment Criteria}

Complete details of these methods have been reported elsewhere (Jacometo et al., 2016). Briefly, during the dry period, cows were housed in a ventilated, sandbedded free-stall barn. Diets were fed for ad libitum intake as a TMR once daily using an individual gate feeding system (American Calan, Northwood, NH) and DMI was recorded daily. First-milking colostrum volume was recorded and IgG content was estimated based on specific gravity with a bovine colostrometer (catalog no. C10978N, Nasco, Fort Atkinson, WI).

Heifer calf enrollment criteria, management after birth, and housing were described in detail elsewhere (Jacometo et al., 2016). Briefly, after birth, calves were weighed, had the navel disinfected with a $7 \%$ tincture of iodine solution (First Priority Inc., Elgin, IL), were vaccinated with TSV II (Pfizer Inc., New York, NY) via nostril application, and received $3.8 \mathrm{~L}$ of first-milking colostrum from the respective dam within $8 \mathrm{~h}$ after birth. If voluntary colostrum intake had not reached 
the $3.8 \mathrm{~L}$ required, calves were force-fed via esophageal tube. A subsample of colostrum $(\sim 150 \mathrm{~mL})$ was frozen at $-20^{\circ} \mathrm{C}$ within $30 \mathrm{~min}$ of collection. The analysis of free AA concentrations (University of Missouri Agricultural Experiment Station Chemical Laboratories, Columbia, MO) was performed in de-fatted colostrum samples (i.e., after centrifugation at $1,000 \times g$ for 30 min at $4^{\circ} \mathrm{C}$ ). Calves were housed in individual outdoor hutches bedded with straw, fed twice daily (AM and PM) with a milk replacer (Advance Excelerate, Milk Specialties, Carpentersville, IL; $28.5 \%$ CP, $15 \%$ fat; supplemented with L-Lys and DL-Met; from 1 to $10 \mathrm{~d}$ of age: $520 \mathrm{~g} / \mathrm{d}, 11$ to $20 \mathrm{~d}$ of age: $680 \mathrm{~g} / \mathrm{d}, 21$ to $35 \mathrm{~d}$ of age: $840 \mathrm{~g} / \mathrm{d}$, and from 36 to $42 \mathrm{~d}$ of age: $420 \mathrm{~g} / \mathrm{d}$ in a single feeding) and had ad libitum access to a starter grain mix (19.9\% CP, $13.5 \% \mathrm{NDF})$. Growth performance including $\mathrm{BW}$ and withers height are reported elsewhere (Jacometo et al., 2016). Calves were weaned at $42 \mathrm{~d}$ of age. All calves remained clinically healthy during the study. No difference was present between groups for colostrum IgG concentration, apparent IgG absorption, calf birth $\mathrm{BW}$, weekly $\mathrm{BW}$, weekly $\mathrm{BW}$ gain, milk replacer intake, starter intake, or withers height (Jacometo et al., 2016).

\section{Sample Collection}

Liver was sampled via puncture biopsy (Swanson et al., 2000) from calves under local anesthesia $(1 \mathrm{~mL}$ s.c. lidocaine- $\mathrm{HCl}, 2 \%$ solution) before the afternoon milk replacer feeding, at approximately $1500 \mathrm{~h}$, on d $4,14,28$, and 50 of age ( $\mathrm{n}=8$ per group). The biopsy instrument consisted of a stainless steel cannula (17 cm in length, o.d. of $7 \mathrm{~mm}$; i.d. of $5 \mathrm{~mm}$ ), and a stainless steel trocar $20 \mathrm{~cm}$ long that fit snugly inside the cannula (Machine Lab, Division of Operations and Maintenance, University of Illinois). Tissue specimens (500-600 mg from 2 punctures of the liver) were stored in liquid $\mathrm{N}_{2}$ until further analysis.

\section{RNA Extraction, cDNA Synthesis, Quantitative PCR, and Design and Evaluation of Primers}

All these procedures were reported previously (Jacometo et al., 2015). Briefly, liver total RNA extraction was performed with the miRNeasy kit (Qiagen, Hilden, Germany) following the manufacturer's protocols. Samples were treated on-column with DNaseI (Qiagen), quantification was accessed using the NanoDrop ND-1000 (NanoDrop Technologies, Rockland, DE), and RNA quality was measured using an Agilent 2100 Bioanalyzer (Agilent, Santa Clara, CA). Samples used in the analysis had a mean RNA integrity number of $7.2 \pm 0.2$. Minimum information for publication of quantitative real-time PCR experiments is reported in Supplemental Table S2 (https://doi.org/10.3168/ jds.2016-11656).

The selected target genes (Figure 1) were methionine adenosyltransferase I, $\alpha(M A T 1 A)$, betaine-homocysteine S-methyltransferase $(B H M T)$, betaine-homocysteine S-methyltransferase 2 (BHMT2), cystathionine gamma-lyase $(C T H)$, cystathionine- $\beta$-synthase $(C B S)$, 5 -methyltetrahydrofolate-homocysteine methyltransferase $(M T R)$, adenosylhomocysteinase $(S A H H)$, phosphatidylethanolamine $N$-methyltransferase (PEMT), cysteine dioxygenase 1, cytosolic (CDO1), cysteine sulfinic acid decarboxylase (CSAD), DNA (cytosine-5)methyltransferase 1 (DNMT1), DNA (cytosine-5)methyltransferase $3 \alpha$ (DNMT3A), DNA (cytosine-5)methyltransferase $3 \beta$ (DNMT3B), glutamate-cysteine ligase, catalytic subunit ( $G C L C$ ), glutathione synthetase $(G S S)$, glutathione reductase $(G S R)$, and glutathione peroxidase 1 (GPX1). For this study, glyceraldehyde3-phosphate dehydrogenase (GAPDH), ubiquitously expressed prefoldin like chaperone $(U X T)$ and ribosomal protein S9 (RPS9) were used as internal control genes, and their geometric mean was used to normalize the mRNA abundance data. The stability of the normalization factor was assessed with geNorm software with a favorable final pairwise variation of 0.20 . Except for DNMT3A, all primer sequences are reported in Osorio et al. (2014a). Primer sequences for DNMT3A (gene ID, 353354; NM_181813.2; 91 bp long) are F.2265, GACAGCAAAGTTAAAGAAAGTACAGACAA and R.2355, ATTCATGACAACAGGGAAAAGTTG.

\section{BHMT Activity Assay}

The activity of BHMT in liver tissue was measured as described previously (Finkelstein and Mudd, 1967), with several modifications described by Garrow (1996). The exact protocol is included in the Supplemental Materials (https://doi.org/10.3168/jds.2016-11656). It is important to note that this assay specifically measured activity of BHMT, which uses betaine as a substrate and not S-methylmethionine, which is a substrate for BHMT2 (Szegedi et al., 2008).

\section{Statistical Analysis}

Data were analyzed with the Proc MIXED procedure of SAS 9.4 (SAS Institute Inc., Cary, NC). Fixed effects in the model were treatment $(\mathbf{T})$, day $(\mathbf{D})$, and their interaction $(\mathbf{T} \times \mathbf{D})$. Random effect was calf within diet. The exponential correlation covariance structure SP for repeated measures was used for analysis of mRNA abundance. Results were $\log _{2}$-scale transformed if needed to comply with normal distribution 
of residuals, and subsequently back-transformed. For cow plasma AA data, the fixed effect in the model was treatment, and the random effect cow within diet. The Kenward-Roger statement was used for computing the denominator degrees of freedom. Least squares means separation between time points was performed using the PDIFF statement. Pearson correlations between BHMT and BHMT activity were performed using the CORR procedure in SAS. Statistical significance was declared at $P \leq 0.05$ and tendencies at $P \leq 0.10$.

\section{RESULTS}

\section{Maternal AA Concentration in Plasma Before Calving}

As expected, feeding RPM to increase the amount of Met in the MP by $10 \mathrm{~g} / \mathrm{d}$ resulted in greater concentrations of Met in plasma before calving (Table 1). Except for Phe, Gln, Gly, homocysteine, and Ser, the concentrations of all other AA and AA derivatives measured were greater $(P<0.05)$ in response to feeding RPM during the last $3 \mathrm{wk}$ prepartum. Those responses were due primarily to consistently greater DMI in cows fed RPM (14.3 vs. $13.2 \mathrm{~kg} / \mathrm{d}$ ).

\section{Colostrum Yield and Total Protein, Free AA, and AA Derivative Concentrations}

Prepartum RPM had no effect $(P=0.82)$ on yield of colostrum, protein, and total AA (Table 2). Similarly, feeding RPM had no effect on concentration of Met or other AA that were detected in the skim fraction of colostrum. It was noteworthy that taurine had the highest concentration among all free AA detected, with Met being less than $0.5 \%$ of total free AA.

\section{Hepatic mRNA Abundance}

Met Cycle and DNA Methylation. Main effects of diet, day, and interactions for genes related to methionine cycle and DNA methylation are reported in Table 3. Maternal supplementation with Met led to a T

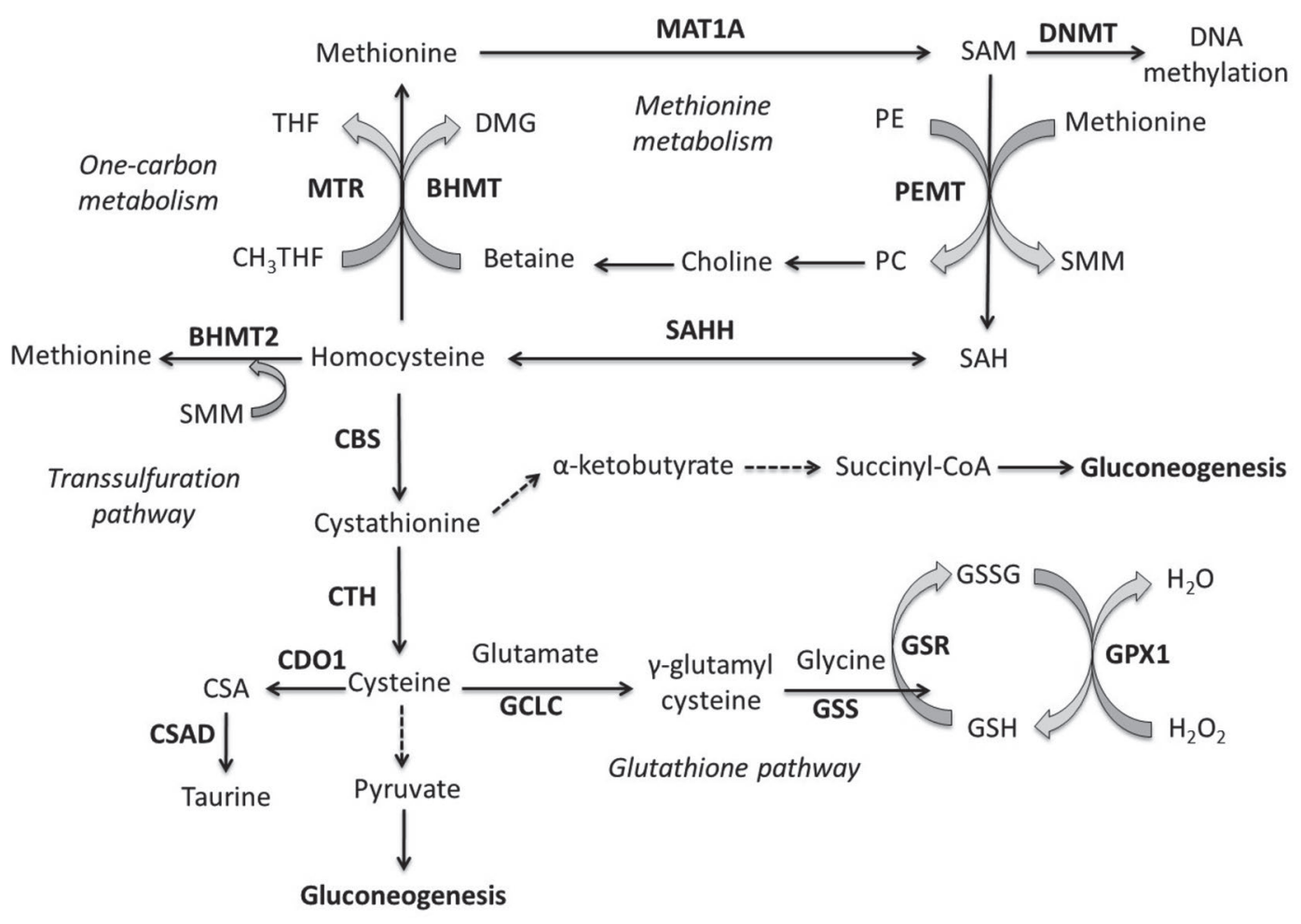

Figure 1. Key genes encoding enzymes of the 1-carbon, methionine, transsulfuration, and glutathione pathways: Met adenosyltransferase 1A $(M A T 1 A)$, phosphatidylethanolamine methyltransferase $(P E M T), S$-adenosylhomocysteine hydrolase $(S A H H)$, betaine homocysteine methyltransferase (BHMT and BHMT2), 5-methyltetrahydrofolate-homocysteine methyltransferase (MTR), cystathionine $\beta$-synthase $(C B S)$, cystathionine $\beta$-lyase $(C T H)$, cysteine dioxygenase 1 , cytosolic $(C D O)$, cysteine sulfinic acid decarboxylase $(C S A D)$, DNA (cytosine-5)-methyltransferase 1 (DNMT1), DNA (cytosine-5)-methyltransferase $3 \alpha$ (DNMT3A) and DNA (cytosine-5)-methyltransferase $3 \beta$ (DNMT3B), glutamate-cysteine ligase, catalytic subunit $(G C L C)$, glutathione synthetase $(G S S)$, glutathione reductase $(G S R)$, and glutathione peroxidase 1 (GPX1) cysteine dioxygenase $1 . \mathrm{SAM}=S$-adenosylmethionine; $\mathrm{SMM}=\mathrm{S}$-methylmethionine; $\mathrm{PE}=$ phosphatidylethanolamine; $\mathrm{PC}=$ phosphatidylcholine; $\mathrm{SAH}$ $=S$-adenosylhomocysteine; THF $=$ tetrahydrofolate; $\mathrm{CH}_{3} \mathrm{THF}=5$-methyltetrahydrofolate; DMG $=$ dimethylglycine; GSSG $=$ oxidized glutathione; GSH = reduced glutathione. 
$\times \mathrm{D}(P<0.05)$ in the abundance of BHMT2, $C B S$, and $S A H H$ partly as a result of greater abundance in MET than CON calves of BHMT2 at d 4,14, and 28 and $C B S$ at d 4 and 14, and greater abundance of $S A H H$ at d 14 . Furthermore, abundance of BHMT2 decreased gradually $(\mathrm{T} \times \mathrm{D})$ from 4 to $50 \mathrm{~d}$ in MET calves. For $C B S$, its abundance over time with MET and CON changed little $(\mathrm{T} \times \mathrm{D})$ between 4 and $28 \mathrm{~d}$ but increased markedly to highest abundance on $\mathrm{d} 50$. Although no $\mathrm{T} \times$ $\mathrm{D}$ were detected, there was greater overall abundance of MAT1A $(P=0.001)$ and lower $C D O 1(P=0.003)$, DNMT1 $(P<0.001)$, and DNMT3A $(P=0.054)$ in MET than CON calves.

Regardless of maternal diet, a time effect was detected for all the genes, but particularly for MAT1A, $P E M T, C S A D$, and DNMT3B $(P<0.001)$ mainly due to a marked increase at $50 \mathrm{~d}$ of age compared with the pre-weaning period. The day effect $(P=0.02)$ for $S A H H$ was mainly due to a marked increase in MET calves at $14 \mathrm{~d}$ of age compared with other times. Abun-

Table 1. Plasma standard free AA, AA derivatives, and urea concentrations at $-10 \mathrm{~d}$ from calving in cows fed the same diet without (control, CON) or with rumen-protected Met at $0.08 \%$ of diet $\mathrm{DM} / \mathrm{d}(\mathrm{MET})$ for the last $21 \mathrm{~d}$ before calving

\begin{tabular}{|c|c|c|c|c|}
\hline \multirow[b]{2}{*}{ Item $(\mu M)$} & \multicolumn{2}{|c|}{ Group } & \multirow[b]{2}{*}{ SEM } & \multirow[b]{2}{*}{$P$-value } \\
\hline & $\mathrm{CON}$ & MET & & \\
\hline \multicolumn{5}{|l|}{ EAA } \\
\hline Arginine & 52.6 & 66.8 & 3.20 & 0.006 \\
\hline Histidine & 52.2 & 62.1 & 2.43 & 0.01 \\
\hline Isoleucine & 88.5 & 109 & 4.40 & 0.001 \\
\hline Leucine & 132 & 159 & 7 & 0.02 \\
\hline Lysine & 57.1 & 80.9 & 5.73 & 0.01 \\
\hline Methionine & 17.8 & 28.2 & 1.60 & 0.0002 \\
\hline Phenylalanine & 42.5 & 45.4 & 1.22 & 0.10 \\
\hline Threonine & 63.1 & 80.0 & 5.14 & 0.03 \\
\hline Tryptophan & 20.5 & 25.5 & 0.64 & 0.01 \\
\hline Valine & 204 & 243 & 11 & 0.03 \\
\hline Taurine & 24.4 & 42.2 & 1.5 & 0.0001 \\
\hline \multicolumn{5}{|l|}{ NEAA } \\
\hline Asparagine & 25.6 & 33.7 & 2.31 & 0.02 \\
\hline Aspartate & 4.09 & 5.72 & 0.45 & 0.02 \\
\hline Alanine & 173 & 201 & 6 & 0.01 \\
\hline Cysteine/cystine & 7.85 & 11.0 & 0.67 & 0.004 \\
\hline Glutamate & 40.5 & 47.6 & 2.25 & 0.04 \\
\hline Glutamine & 277 & 303 & 15 & 0.23 \\
\hline Glycine & 234 & 248 & 18 & 0.59 \\
\hline Proline & 49.3 & 64.1 & 3.14 & 0.004 \\
\hline Serine & 70.5 & 82.0 & 5.03 & 0.13 \\
\hline Tyrosine & 37.0 & 44.9 & 2.61 & 0.05 \\
\hline \multicolumn{5}{|l|}{ AA derivatives } \\
\hline Cystathionine & 1.98 & 2.56 & 0.17 & 0.03 \\
\hline Homocystine & 4.39 & 5.67 & 0.70 & 0.21 \\
\hline $\mathrm{BCAA}^{1}$ & 425 & 511 & 24 & 0.02 \\
\hline $\mathrm{EAA}^{2}$ & 731 & 900 & 39 & 0.007 \\
\hline NEAA & 911 & 1,029 & 40 & 0.05 \\
\hline EAA/NEAA & 0.82 & 0.88 & 0.04 & 0.39 \\
\hline Urea & 4,172 & 4,101 & 236 & 0.83 \\
\hline
\end{tabular}

${ }^{1} \Sigma$ branched-chain AA.

${ }^{2} \Sigma$ EAA. dance of CDO1, MTR, and BHMT increased $(P<$ $0.05)$ from 4 to $14 \mathrm{~d}$ of age, whereas $C T H$ decreased $(P=0.007)$. The day effect observed for BHMT and BHMT2 abundance $(P<0.001$ for both $)$ was mainly due to a decrease in abundance from 14 to $28 \mathrm{~d}$ of age. The DNA methyltransferases DNMT1, DNMT3A, and DNMT3B increased gradually over time regardless of maternal treatment $(P<0.001$ for both). For $D N M T 3 B$, the abundance at d 50 was $\sim 2.5$-fold higher than at $4 \mathrm{~d}$ of age.

Glutathione Metabolism. Main effects of diet, day, and interactions for genes related to glutathione metabolism are reported in Table 3. Maternal supplementation with Met led to a $\mathrm{T} \times \mathrm{D}(P<0.05)$ in the abundance of $G C L C, G S S$, and $G S R$ as a result of greater abundance in MET than CON calves of $G C L C$ and $G S R$, but lower abundance of $G S S$ on d 4 of age. Abundance of GSS remained greater in MET than CON calves at $50 \mathrm{~d}$ of age. Furthermore, within treatments, GCLC abundance increased gradually in $\mathrm{CON}$ calves from 4 to peak values at 28 and $50 \mathrm{~d}$ of age. In contrast, MET calves experienced a decrease in $G C L C$ from 4 to $14 \mathrm{~d}$ followed by a gradual increase to peak values at $50 \mathrm{~d}$ of age. The abundance of $G S S$ decreased $(\mathrm{T} \times \mathrm{D})$ between 4 and $28 \mathrm{~d}$ in both MET and CON calves. For GSR, abundance changed little from 4 to 28

Table 2. Colostrum and protein yield, and total standard free AA concentrations in colostrum in cows fed the same diet without (control, CON) or with rumen-protected Met at $0.08 \%$ of diet DM/d (MET) for the last $21 \mathrm{~d}$ before calving

\begin{tabular}{|c|c|c|c|c|}
\hline \multirow[b]{2}{*}{ Item } & \multicolumn{2}{|c|}{ Group } & \multirow[b]{2}{*}{ SEM } & \multirow[b]{2}{*}{$P$-value } \\
\hline & $\mathrm{CON}$ & MET & & \\
\hline Colostrum yield (kg) & 7.40 & 7.81 & 1.25 & 0.82 \\
\hline Protein yield $(\mathrm{kg})$ & 1.42 & 1.54 & 0.23 & 0.70 \\
\hline Total free $\mathrm{AA}^{\mathrm{l}}(\mu \mathrm{g} / \mathrm{mL})$ & 321 & 281 & 21.7 & 0.20 \\
\hline \multicolumn{5}{|l|}{$\operatorname{EAA}(\%$ of total $)$} \\
\hline Arginine & 1.65 & 1.73 & 0.21 & 0.96 \\
\hline Histidine & 0.37 & 0.38 & 0.07 & 0.96 \\
\hline Isoleucine & 1.30 & 1.17 & 0.26 & 0.57 \\
\hline Leucine & 1.57 & 1.68 & 0.37 & 0.97 \\
\hline Lysine & 1.70 & 1.62 & 0.27 & 0.75 \\
\hline Methionine & 0.26 & 0.32 & 0.08 & 0.62 \\
\hline Phenylalanine & 1.06 & 1.14 & 0.30 & 0.97 \\
\hline Threonine & 1.40 & 1.27 & 0.11 & 0.25 \\
\hline Valine & 4.25 & 3.48 & 0.70 & 0.40 \\
\hline Taurine & 68.8 & 70.7 & 3.10 & 0.72 \\
\hline \multicolumn{5}{|l|}{ NEAA ( $\%$ of total) } \\
\hline Aspartate & 0.71 & 0.82 & 0.13 & 0.47 \\
\hline Alanine & 1.65 & 1.42 & 0.24 & 0.46 \\
\hline Cysteine/cystine & 0.16 & 0.29 & 0.07 & 0.14 \\
\hline Glutamate & 6.36 & 6.40 & 0.53 & 0.96 \\
\hline Glycine & 2.70 & 1.85 & 0.39 & 0.11 \\
\hline Proline & 3.85 & 3.48 & 0.43 & 0.51 \\
\hline Serine & 1.24 & 1.18 & 0.09 & 0.53 \\
\hline Tyrosine & 0.97 & 1.07 & 0.22 & 0.79 \\
\hline
\end{tabular}

${ }^{1} \Sigma$ of standard free AA. 
Table 3. Abundance of genes related to methionine metabolism, DNA methylation, glutathione metabolism, and hepatic betaine-homocysteine S-methyltransferase (BHMT) activity in calves born to dams fed a conventional diet (CON) or CON supplemented with rumen-protected Met (MET) during the last $21 \mathrm{~d}$ pre-partum

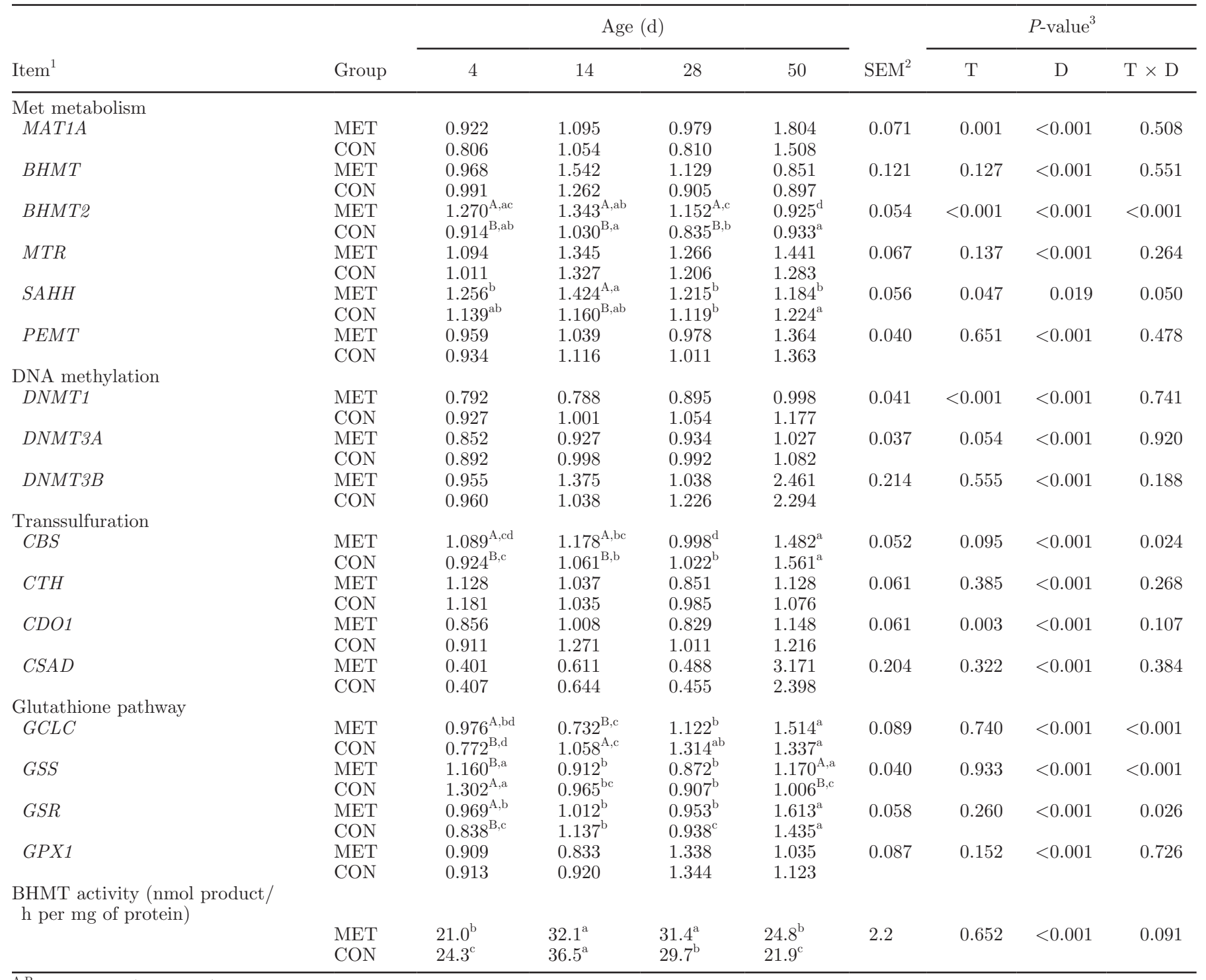

$\overline{\mathrm{A}, \mathrm{B}}$ Differences $(P<0.05)$ between treatments within time point.

${ }^{\mathrm{a}-\mathrm{e}}$ Differences $(P<0.05)$ between time points within treatment.

${ }^{1}$ Gene symbols: MAT1A, methionine adenosyltransferase I, $\alpha ; B H M T$, betaine-homocysteine S-methyltransferase; $B H M T 2$, betaine-homocysteine S-methyltransferase $2 ; C T H$, cystathionine gamma-lyase; $C B S$, cystathionine- $\beta$-synthase; $M T R, 5$-methyltetrahydrofolate-homocysteine methyltransferase; $S A H H$, adenosylhomocysteinase; $P E M T$, phosphatidylethanolamine N-methyltransferase; CDO1, cysteine dioxygenase 1, cytosolic; CSAD, cysteine sulfinic acid decarboxylase; DNMT1, DNA (cytosine-5)-methyltransferase 1; DNMT3A, DNA (cytosine-5)-methyltransferase 3 a; DNMT3B, DNA (cytosine-5)-methyltransferase $3 \beta ; G C L C$, glutamate-cysteine ligase, catalytic subunit; GSS, glutathione synthetase; GSR, glutathione reductase; GPX1, glutathione peroxidase 1.

${ }^{2}$ Greatest SEM is shown.

${ }^{3} P$-value for treatment $(\mathrm{T})$, day $(\mathrm{D})$, and their interaction $(\mathrm{T} \times \mathrm{D})$.

$\mathrm{d}$ of age and then increased markedly at $50 \mathrm{~d}$ in both MET and CON. However, its abundance increased at $50 \mathrm{~d}$ in MET than CON calves. Regardless of maternal treatment, GPX1 increased $(P<0.001$ for both) its abundance over time to a peak at $\mathrm{d} 28$ followed by a decrease at d 50 .

\section{BHMT Activity}

Maternal supplementation with Met did not affect $(P=0.652)$ overall hepatic BHMT activity. However, a trend $(P=0.091)$ was observed for a $\mathrm{T} \times \mathrm{D}$ mainly due to an increase in activity regardless of treatment 
between 4 and $14 \mathrm{~d}$ of age and a decrease between $\mathrm{d}$ 28 and 50 (Table 3). Furthermore, activity remained higher at 14 and $28 \mathrm{~d}$ in MET calves followed by a decrease at $50 \mathrm{~d}$. In contrast, activity in CON calves decreased gradually from $14 \mathrm{~d}$ through $50 \mathrm{~d}$. A time effect $(P<0.001)$ was detected characterized by a peak in activity at $\mathrm{d} 14$ of age followed by a return to initial values at $50 \mathrm{~d}$ of age.

\section{DISCUSSION}

To generate SAM, which is essential for several transmethylation reactions, the first step in metabolism of Met involves the binding of adenosyl, mediated by the enzyme Met adenosyltransferase (Martinov et al., 2010). Phosphatidylcholine biosynthesis takes place after the transfer of methyl groups from SAM to phosphatidylethanolamine via phosphatidylethanolamine $N$ methyltransferase (PEMT), linking PC and 1-carbon metabolism in the liver (Obeid and Herrmann, 2009). After donating the methyl groups, SAM becomes Sadenosyl-homocysteine (SAH), which is subsequently hydrolyzed to homocysteine. Then, 2 options are possible: (1) homocysteine can either be remethylated to Met through the folate cycle [through 5-methyltetrahydrofolate-homocysteine methyltransferase (MTR) activity], through oxidation choline (via BHMT and BHMT2 activity), or both; or (2) homocysteine can be converted (via the transsulfuration pathway) to cystathionine, and then catabolized to Cys (Mato et al., 2008). Cysteine can enter the glutathione metabolism pathway or generate taurine (Mato et al., 2008).

The fact that MET and CON calves had similar intakes of milk replacer and starter during the study (Jacometo et al., 2016) is suggestive that the greater overall abundance of MAT1A,SAHH, and BHMT2 in MET calves was due in part to greater maternal availability of Met during the last $\sim 3$ wk prepartum. This idea is partly supported by the greater concentration of Met in plasma of MET cows at $-10 \mathrm{~d}$ from calving (Table 1). Perhaps the most striking response underscoring the potential carry-over effect of maternal Met was the greater abundance of BHMT2 and $S A H H$ at 4 and 14 $\mathrm{d}$ of age in MET than CON calves. Because feed intake did not differ, we speculate that the liver of MET calves might have been better equipped to metabolize choline and homocysteine to Met or to channel homocysteine through the transsulfuration pathway (e.g., increase flux through the cycle) at least during the first $14 \mathrm{~d}$ of age when calves relied the most on milk replacer as a source of nutrients. Because colostrum AA profiles did not differ, it remains to be determined if other metabolites could have played a role on the calf liver response (at least at the $4 \mathrm{~d}$ time point). In humans it was recently demonstrated that gestational diabetes mellitus altered the colostrum proteome (Grapov et al., 2015); thus, the idea that prenatal nutrition of the mother or its physiologic effect on the mother could alter colostrum composition is not far-fetched.

A crucial role of methionine adenosyltransferase (MAT) in neonatal Met metabolism was first determined in studies with rats, which demonstrated that its activity during the first $30 \mathrm{~d}$ of life was at almost maximal level already at birth (Eloranta, 1977). Subsequent studies with sheep liver underscored the role of MAT in the production of SAM, and established (as in rodents) that substrate (Met) and product (SAM) can directly influence the reaction rate in vivo [e.g., accumulation of SAM inhibited MAT activity (Xue et al., 1989)]. With this in mind, it is noteworthy that $S A H H$ and MAT1A mRNA accounted for $\sim 90 \%$ and $\sim 2 \%$ of all the transcripts examined (Supplemental Table S3; https://doi.org/10.3168/jds.2016-11656), which can be taken as an indication of their key role in the control of Met metabolism in the young calf. Both of the BHMT transcripts accounted for $\sim 3 \%$ of all transcripts examined, also suggesting their importance in the context of neonatal utilization of choline for Met synthesis (Figure $1)$.

The activity of SAHH is responsive to availability of substrate and its inhibition can cause accumulation of SAH, consequently suppressing the use of SAM for transmethylation reactions [e.g., via DNA methyltransferase enzymes (DNMT); Lee et al., 2011]. In nonruminants, MAT1A activity also is responsive to dose of Met (Garcia-Trevijano et al., 2000). However, responses in the calves cannot be solely explained by dietary Met intake from colostrum, milk replacer, and starter because we did not detect statistical differences between groups (Jacometo et al., 2016). Therefore, we speculate that the overall greater $S A H H$ and MAT1A abundance in MET calves might have been due to a "priming" effect in utero. The lower overall abundance of DNMT1 and DNMT3A in MET calves supports a priming effect, as well as data from humans demonstrating that hypermethylation of MAT1A could control its transcription (Tomasi et al., 2012). Although we did not assess MAT1A methylation status, our previous work revealed that feeding cows RPM from -21 through $30 \mathrm{~d}$ postpartum altered global liver DNA methylation and peroxisome proliferator activated receptor $\alpha(P P A R A)$ methylation of certain regions of its promoter at the end of the study. Future research to clarify the role of cow Met supplementation, colostrum metabolite composition, and their potential interactions on DNA methylation in liver is warranted.

To what extent activity of MAT1A and SAHH could have been primed to respond to the extrauterine envi- 
ronment remains to be determined. In this context it is important to note that abundance of SAHH in rodents, for example, correlates positively with activity of the enzyme [i.e., highest mRNA abundance in liver agreed with the highest enzymatic activity in that tissue (Finkelstein, 1967; Eloranta and Raina, 1977)]. We speculate that one important role for SAHH in the neonatal liver could be the synthesis of glutathione, a potent intracellular antioxidant. This idea is partly supported by the fact that bovine mammary gland hydrolyzes circulating glutathione to free AA due to the high activity of $\gamma$-glutamyl transpeptidase (Baumrucker et al., 1981); hence, colostral or mature milk concentration of glutathione is quantitatively very low. Early work on activity of SAHH in rodent liver extracts demonstrated that $\mathrm{SAH}$ is readily hydrolyzed to homocysteine as long as homocysteine is further metabolized (De La Haba and Cantoni, 1959). Because of the high concentrations of CP $(28.5 \%)$ and the fact that the milk replacer fed had added Met (see Materials and Methods), it is unlikely that SAH would have accumulated in the liver. Furthermore, data from neonatal sheep liver demonstrated that activity of PEMT, which uses SAM as substrate, increased $\sim 3$-fold between $\mathrm{d} 1$ and 10 of age and remained $\sim 2.5$-fold higher at $40 \mathrm{~d}$ of age, indicating that an important use of SAM in postnatal liver is for the synthesis of SAH and PC (Xue and Snoswell, 1986). The fact that $S A H H$ abundance was upregulated in the liver of RPM-supplemented cows (Osorio et al., 2014a) and they had greater concentrations of glutathione in liver tissue underscores the importance of this enzyme to bovine liver Met metabolism during stressful periods of their life (i.e., transition into lactation and postnatal life).

Although it reached peak abundance after weaning, we speculate that the lack of effect on PEMT indicates that its role in de novo synthesis of choline from recycling of PC during the pre-weaning period is modest. The overall longitudinal pattern of PEMT abundance somewhat resembles the longitudinal activity for this enzyme detected in neonatal sheep liver between 1 and $40 \mathrm{~d}$ of age, but in the case of sheep activity more than doubled between d 1 and 10 or 40 of age (Xue and Snoswell, 1986). It should be noted that sheep used in that study were reared strictly on their ewes' milk (i.e., those animals would have had greater needs to synthesize PC for very-low density lipoprotein synthesis and export). Along with differences in $S A H H$ and BHMT2, we speculate that the lack of effect in MET calves on $M T R$ abundance coupled with its gradual increase to peak values after weaning is indicative of a more important role of this enzyme for synthesis of Met once the ruminal environment has matured (i.e., when microbial synthesis of folic acid and vitamin $\mathrm{B}_{6}$ likely is sufficient to meet the calf's needs). This idea is partly supported by the gradual decrease in abundance of $B H M T$ and BHMT2 over time.

The peak in total BHMT activity at $14 \mathrm{~d}$ and the gradual decrease until $50 \mathrm{~d}$ of age regardless of maternal diet agreed with mRNA abundance data of BHMT. This temporal profile in BHMT activity is similar to that detected in neonatal sheep during the first $10 \mathrm{~d}$ of life, but differs in the sense that sheep liver still had greater BHMT activity between 10 and $40 \mathrm{~d}$ of age compared with d 1 (Xue and Snoswell, 1986). We also have detected a parallel increase in BHMT mRNA abundance and activity in cow liver between the preand postpartum period, indicating that mRNA and activity of this enzyme are correlated in ruminants (Zhou et al., 2017). It is well established in nonruminants that BHMT activity is closely associated with dietary methyl donor availability (Emmert et al., 1996), but its precise regulation in ruminants remains to be determined. It is noteworthy that human fetal liver BHMT protein abundance and enzyme activity are positively correlated (Feng et al., 2011); thus, if active uptake of circulating choline is present through the placenta or from colostrum, it is possible that such an effect may elicit changes in the genes and enzymes composing the pathway.

The lack of change in abundance of $C B S$ and $C T H$ in Met calves was indicative of a greater effect of maternal treatment or its effect on colostrum composition on the Met metabolism pathway than both the transsulfuration and glutathione metabolism pathways. This is partly supported by data from neonatal sheep liver demonstrating that activity of CBS is markedly lower than activity of BHMT, MTR, and choline oxidase (Xue and Snoswell, 1986). Despite this, the longitudinal pattern of CBS activity in sheep liver was already almost maximal at $1 \mathrm{~d}$ compared with 10 and $40 \mathrm{~d}$ of age (Xue and Snoswell, 1986), which seems to agree with the overall pattern of $C B S$ abundance in the present study.

In rodents, the mRNA abundance of CSAD is positively correlated with its activity in liver, but no such relationship seems to exist for CDO1 (Bella et al., 1999). Regulation of CDO1 in rodents is primarily through changes in intracellular levels of Cys [i.e., elevated Cys promotes enzyme stability and catalytic efficiency but low Cys levels promote ubiquitination and proteasomal degradation (Stipanuk and Ueki, 2011)]. Whether similar mechanisms take place in the bovine liver is unknown. However, the fact that abundance of $G C L C$ and GSR especially on d 4 of age was greater in MET calves led us to speculate that the lower overall abundance of $C D O 1$ in MET calves and the similar abundance of $C S A D$ in both groups could have increased Cys availability for glutathione synthe- 
sis through GCLC and GSR. Unlike CDO1, there is evidence for transcriptional regulation of GCLC and GSR, which in turn determines enzymatic activity and protein abundance (Mullineaux and Creissen, 1997; Rahman and MacNee, 2000; Lu, 2009). Key transcription regulators include nuclear receptor subfamily 2 group $\mathrm{F}$ member 2, activator protein-1, and nuclear factor kappa- $\beta$, all of which seem to act through the "antioxidant response element" on the DNA sequence (Lu, 2009). Whether these transcriptional mechanisms occur in the bovine liver is unknown.

It is noteworthy that although taurine concentration in bovine colostrum is highest among all the free AA (Table 3), it decreases markedly through the mature milk stage (Zanker et al., 2000). Because commercial milk replacers have very low (Piantoni et al., 2012) concentrations of taurine, the activity of SAHH could regulate the amount of homocysteine available for enzymes in the transsulfuration pathway (CBS and CTH). This idea is partly supported by early work on activity of MAT and SAHH in rat liver extracts demonstrating that 1) activity of MAT was $\sim 140$-fold greater than SAHH already at birth and changed little compared with d 72 of life (Eloranta, 1977), and 2) research demonstrating that feeding a vitamin $\mathrm{B}_{6}$-deficient diet markedly increased concentration of hepatic $\mathrm{SAH}$ and only increased SAM concentration and activity of SAHH slightly (Eloranta et al., 1976). The accumulation of SAH in that study agreed with data demonstrating that $\mathrm{SAHH}$ is readily hydrolyzed to homocysteine as long as homocysteine is further metabolized (De La Haba and Cantoni, 1959; i.e., without vitamin $\mathrm{B}_{6}$ the activity of MTR is inhibited).

The process of DNA methylation, the best-characterized epigenetic mechanism, is dynamically regulated by the activity of DNMT. In mammals, activity of DNMT3A and DNMT3B helps establish methylation patterns during embryonic development via de novo methylation, whereas DNMT1 is responsible for maintenance of 5'-C-phosphate-G-3' island methylation patterns ( $\mathrm{Li}$ and Zhang, 2014). In the context of the Met pathway, we speculate that the lower overall abundance of DNMT1 and DNMT3A in MET calves could be interpreted in part as a mechanism to primarily generate homocysteine and also a mechanism to control methylation reactions (e.g., decrease use of SAM for methylation of DNA). Greater synthesis of homocysteine is partly supported by the observed changes in MAT1A and $S A H H$ in Met calves.

Whether Met availability itself can control methylation in the bovine is unclear, but data from rodents fed betaine or choline indicate that such role is feasible (Wang et al., 2013, 2014). In this context, it is noteworthy that the $D N M T$ transcripts accounted for
$<0.05 \%$ of all mRNA measured but their abundance increased over time and for DNMT3B it was $\sim 2.5$-fold higher at $50 \mathrm{~d}$ compared with $4 \mathrm{~d}$. These responses underscored a potentially key role in utilization of SAM as the calf matures. Various methyltransferases besides DNMT could compete for SAM, and in particular the activity of glycine $N$-methyltransferase (Kerr, 1972), guanidinoacetate $N$-methyltransferase, and PEMT in neonatal ruminant liver seem to be of physiologic importance (Xue and Snoswell, 1986). Data from a recent study detected greater global DNA methylation in adult compared with fetal human liver tissue but it was not associated with lower gene transcription (Huse et al., 2015). A previous study from our group also detected greater hepatic abundance of DNMT3A in response to supplemental Met, which we proposed was a physiologic response in the liver to coordinate hepatic adaptations to lactation (Osorio et al., 2014a).

It is becoming apparent that cow nutrition during the dry period can induce differences in the oxidative stress status of the young calf. The antioxidant capacity of an organism is especially relevant during stressful periods (Spears and Weiss, 2008; e.g., during the first days of life and around weaning). A recent study demonstrated that maternal dietary energy density during the last 21 d of gestation altered neonatal antioxidant capability in calves (i.e., lower compared with greater maternal dietary energy levels; 5.25 vs. $6.48 \mathrm{MJ} / \mathrm{kg}$ of $\mathrm{DM}$ ) resulted in lower total antioxidant capacity and superoxide dismutase concentration in plasma whereas glutathione peroxidase and maleic dialdehyde concentrations at birth were higher (Gao et al., 2012). In addition, we detected lower concentrations of systemic biomarkers of oxidative stress and inflammation in calves born to cows supplemented with a blend of organic $\mathrm{Cu}, \mathrm{Mn}, \mathrm{Zn}$, and Co during the last $30 \mathrm{~d}$ of pregnancy (Jacometo et al., 2015). Independent of maternal treatment, the few published data clearly underscore the gradual maturation of these pathways during postnatal growth and likely represent an important event for the establishment of body defenses.

Glutathione peroxidase is a key antioxidant enzyme catalyzing the oxidation of glutathione to control the concentration of hydrogen peroxide (Wu et al., 2010). Supplementation of Met during the transition period effectively increased the hepatic concentration of total glutathione in dairy cows (Osorio et al., 2013), despite causing a decrease in the hepatic abundance of some enzymes $(G C L C, G S S)$ involved in glutathione metabolism but upregulating GPX1 over time (Osorio et al., 2014a). Those responses were associated with lower oxidative stress and a dampened inflammatory response (Osorio et al., 2013, 2014b). 
At least from the results of $G C L C$ and $G S R$ at 4 and $14 \mathrm{~d}$ of age in the present study, it appears that the mechanisms controlling these genes as a function of maternal Met seem to differ from those in transition cow liver. The relative abundance of all transcripts associated with glutathione metabolism was below $0.5 \%$ of total transcripts measured, and among them, the fact that $G C L C$ was more abundant than GSR and $G S S$ led us to speculate that availability of Cys and homocysteine are potentially more important for glutathione synthesis.

Although MET calves in this study had lower concentrations of reactive oxygen metabolites and tended to have lower concentrations of ceruloplasmin in plasma (Jacometo et al., 2016), the differences relative to CON calves were modest indicating that both groups did not experience a marked or sustained period of stress, hence the lack of difference in GPX1 between treatments. The temporal increase in abundance of $G C L C, G S R$, and $G P X 1$ agree with the increases in the concentrations of various biomarkers of inflammation and oxidative stress (Jacometo et al., 2016), indicating that these physiologic responses might be a normal component of the early growth phase in the calf.

\section{CONCLUSIONS}

Overall, our findings provide evidence that the maternal supplementation with Met during the last 3 to 4 wk of gestation directly through an effect in utero or indirectly through altering colostrum metabolite composition can affect the hepatic abundance of genes associated with Met metabolism, DNA methylation, and transsulfuration. The observed changes at the mRNA abundance level agree with data demonstrating faster maturation of gluconeogenesis, and underscore the metabolic interrelationships among these pathways (Figure 1). Although several of the analyzed enzymes show evidence for transcriptional regulation, further research is needed to fully understand mechanisms of regulation. In addition to the need for enzyme activity data, more in-depth epigenetic (e.g., DNA methylation, microRNA profiles) and metabolomic analyses could enhance our understanding of the role of maternal methyl donor nutrition during late pregnancy and the role of colostrum composition on the functional adaptations of neonatal liver.

\section{ACKNOWLEDGMENTS}

Carolina Jacometo was supported in part by a fellowship from Coordenação de Aperfeiçoamento de Pessoal de Nível Superior (CAPES, Brasilia, Brazil) from the Brazilian Ministry of Education (Brasilia, Brazil), and by Hatch funds under project ILLU-538-914, National Institute of Food and Agriculture (Washington, DC).

\section{REFERENCES}

Baumrucker, C. R., P. A. Pocius, and T. L. Riss. 1981. Glutathione utilization by lactating bovine mammary secretory tissue in vitro. Biochem. J. 198:243-246.

Bella, D. L., L. L. Hirschberger, Y. Hosokawa, and M. H. Stipanuk. 1999. Mechanisms involved in the regulation of key enzymes of cysteine metabolism in rat liver in vivo. Am. J. Physiol. 276:E326E335.

Bertolo, R. F., and L. E. McBreairty. 2013. The nutritional burden of methylation reactions. Curr. Opin. Clin. Nutr. Metab. Care 16:102-108. https://doi.org/10.1097/MCO.0b013e32835ad2ee.

Chmurzynska, A. 2010. Fetal programming: link between early nutrition, DNA methylation, and complex diseases. Nutr. Rev. 68:8798. https://doi.org/10.1111/j.1753-4887.2009.00265.x.

Coelho, C. N., J. A. Weber, N. W. Klein, W. G. Daniels, and T. A. Hoagland. 1989. Whole rat embryos require methionine for neural tube closure when cultured on cow serum. J. Nutr. 119:1716-1725.

De La Haba, G., and G. L. Cantoni. 1959. The enzymatic synthesis of S-adenosyl-L-homocysteine from adenosine and homocysteine. J. Biol. Chem. 234:603-608.

Eloranta, T. O. 1977. Tissue distribution of S-adenosylmethionine and S-adenosylhomocysteine in the rat. Effect of age, sex and methionine administration on the metabolism of S-adenosylmethionine, S-adenosylhomocysteine and polyamines. Biochem. J. 166:521-529.

Eloranta, T. O., E. O. Kajander, and A. M. Raina. 1976. A new method for the assay of tissue. S-adenosylhomocysteine and S-adenosylmethione. Effect of pyridoxine deficiency on the metabolism of S-adenosylhomocysteine, S-adenosylmethionine and polyamines in rat liver. Biochem. J. 160:287-294.

Eloranta, T. O., and A. M. Raina. 1977. S-adenosylmethionine metabolism and its relation to polyamine synthesis in rat liver. Effect of nutritional state, adrenal function, some drugs and partial hepatectomy. Biochem. J. 168:179-185.

Emmert, J. L., T. A. Garrow, and D. H. Baker. 1996. Hepatic betainehomocysteine methyltransferase activity in the chicken is influenced by dietary intake of sulfur amino acids, choline and betaine. J. Nutr. 126:2050-2058.

Feng, Q., K. Kalari, B. L. Fridley, G. Jenkins, Y. Ji, R. Abo, S. Hebbring, J. Zhang, M. D. Nye, J. S. Leeder, and R. M. Weinshilboum. 2011. Betaine-homocysteine methyltransferase: Human liver genotype-phenotype correlation. Mol. Genet. Metab. 102:126-133. https://doi.org/10.1016/j.ymgme.2010.10.010.

Finkelstein, J. D. 1967. Methionine metabolism in mammals-Effects of age diet and hormones on three enzymes of the pathway in rat tissues. Arch. Biochem. Biophys. 122:583-590. https://doi. org/10.1016/0003-9861(67)90162-2.

Finkelstein, J. D., and S. H. Mudd. 1967. Trans-sulfuration in mammals. The methionine-sparing effect of cystine. J. Biol. Chem. 242:873-880.

Gao, F., Y. C. Liu, Z. H. Zhang, C. Z. Zhang, H. W. Su, and S. L. Li. 2012. Effect of prepartum maternal energy density on the growth performance, immunity, and antioxidation capability of neonatal calves. J. Dairy Sci. 95:4510-4518.

Garcia-Trevijano, E. R., M. U. Latasa, M. V. Carretero, C. Berasain, J. M. Mato, and M. A. Avila. 2000. S-adenosylmethionine regulates MAT1A and MAT2A gene expression in cultured rat hepatocytes: A new role for S-adenosylmethionine in the maintenance of the differentiated status of the liver. FASEB J. 14:2511-2518. https://doi.org/10.1096/fj.00-0121com.

Garrow, T. A. 1996. Purification, kinetic properties, and cDNA cloning of mammalian betaine-homocysteine methyltransferase. J. Biol. Chem. 271:22831-22838.

Grapov, D., D. G. Lemay, D. Weber, B. S. Phinney, I. R. Azulay Chertok, D. S. Gho, J. B. German, and J. T. Smilowitz. 2015. The human colostrum whey proteome is altered in gestational diabetes mellitus. J. Proteome Res. 14:512-520. https://doi.org/10.1021/ pr500818d. 
Huse, S. M., P. A. Gruppuso, K. Boekelheide, and J. A. Sanders. 2015. Patterns of gene expression and DNA methylation in human fetal and adult liver. BMC Genomics 16:981 https://doi.org/10.1186/ s12864-015-2066-3.

Jacometo, C. B., J. S. Osorio, M. Socha, M. N. Correa, F. PiccioliCappelli, E. Trevisi, and J. J. Loor. 2015. Maternal consumption of organic trace minerals alters calf systemic and neutrophil mRNA and microRNA indicators of inflammation and oxidative stress. J. Dairy Sci. 98:7717-7729. https://doi.org/10.3168/jds.2015-9359.

Jacometo, C. B., Z. Zhou, D. Luchini, E. Trevisi, M. N. Correa, and J. J. Loor. 2016. Maternal rumen-protected methionine supplementation and its effect on blood and liver biomarkers of energy metabolism, inflammation, and oxidative stress in neonatal Holstein calves. J. Dairy Sci. 99:6753-6763. https://doi.org/10.3168/ jds.2016-11018.

Kerr, S. J. 1972. Competing methyltransferase systems. J. Biol. Chem. 247:4248-4252.

Lee, Y., L. S. Jeong, S. Choi, and C. Hyeon. 2011. Link between allosteric signal transduction and functional dynamics in a multisubunit enzyme: S-adenosylhomocysteine hydrolase. J. Am. Chem. Soc. 133:19807-19815. https://doi.org/10.1021/ja2066175.

Li, E., and Y. Zhang. 2014. DNA methylation in mammals. Cold Spring Harb. Perspect. Biol. 6:a019133 https://doi.org/10.1101/ cshperspect.a019133.

Lu, S. C. 2009. Regulation of glutathione synthesis. Mol. Aspects Med. 30:42-59. https://doi.org/10.1016/j.mam.2008.05.005.

Martinov, M. V., V. M. Vitvitsky, R. Banerjee, and F. I. Ataullakhanov. 2010. The logic of the hepatic methionine metabolic cycle. Biochim. Biophys. Acta 1804:89-96. https://doi.org/10.1016/j. bbapap.2009.10.004.

Mato, J. M., M. L. Martinez-Chantar, and S. C. Lu. 2008. Methionine metabolism and liver disease. Annu. Rev. Nutr. 28:273-293. https://doi.org/10.1146/annurev.nutr.28.061807.155438.

Mullineaux, P. M., and G. Creissen. 1997. Glutathione reductase: Regulation and role in oxidative stress. Pages 667-713 in Oxidative Stress and the Molecular Biology of Antioxidant Defenses. J. G. Scandalios, ed. Cold Spring Harbor Laboratory Press, New York, NY.

NRC. 2001. Nutrient Requirements of Dairy Cattle. 7th rev. ed. Natl. Acad. Press, Washington, DC.

O'Neill, R. J., P. B. Vrana, and C. S. Rosenfeld. 2014. Maternal methyl supplemented diets and effects on offspring health. Front. Genet. 5:289. https://doi.org/10.3389/fgene.2014.00289.

Obeid, R., and W. Herrmann. 2009. Homocysteine and lipids: S-adenosyl methionine as a key intermediate. FEBS Lett. 583:12151225. https://doi.org/10.1016/j.febslet.2009.03.038.

Osorio, J. S., P. Ji, J. K. Drackley, D. Luchini, and J. J. Loor. 2014a. Smartamine $M$ and MetaSmart supplementation during the peripartal period alter hepatic expression of gene networks in 1-carbon metabolism, inflammation, oxidative stress, and the growth hormone-insulin-like growth factor 1 axis pathways. J. Dairy Sci. 97:7451-7464. https://doi.org/10.3168/jds.2014-8680.

Osorio, J. S., E. Trevisi, M. A. Ballou, G. Bertoni, J. K. Drackley, and J. J. Loor. 2013. Effect of the level of maternal energy intake prepartum on immunometabolic markers, polymorphonuclear leukocyte function, and neutrophil gene network expression in neonatal Holstein heifer calves. J. Dairy Sci. 96:3573-3587. https://doi. org $/ 10.3168 /$ jds.2012-5759.

Osorio, J. S., E. Trevisi, P. Ji, J. K. Drackley, D. Luchini, G. Bertoni, and J. J. Loor. 2014b. Biomarkers of inflammation, metabolism, and oxidative stress in blood, liver, and milk reveal a better immunometabolic status in peripartal cows supplemented with Smartamine M or MetaSmart. J. Dairy Sci. 97:7437-7450. https://doi. org/10.3168/jds.2013-7679.

Piantoni, P., K. M. Daniels, R. E. Everts, S. L. Rodriguez-Zas, H. A. Lewin, W. L. Hurley, R. M. Akers, and J. J. Loor. 2012. Level of nutrient intake affects mammary gland gene expression profiles in preweaned Holstein heifers. J. Dairy Sci. 95:2550-2561. https:// doi.org/10.3168/jds.2011-4539.

Rahman, I., and W. MacNee. 2000. Regulation of redox glutathione levels and gene transcription in lung inflammation: Therapeutic approaches. Free Radic. Biol. Med. 28:1405-1420.
Sinclair, K. D., P. C. Garnsworthy, G. E. Mann, and L. A. Sinclair. 2014. Reducing dietary protein in dairy cow diets: Implications for nitrogen utilization, milk production, welfare and fertility. Animal 8:262-274. https://doi.org/10.1017/S1751731113002139.

Spears, J. W., and W. P. Weiss. 2008. Role of antioxidants and trace elements in health and immunity of transition dairy cows. Vet. J. 176:70-76. https://doi.org/10.1016/j.tvjl.2007.12.015.

Stipanuk, M. H., and I. Ueki. 2011. Dealing with methionine/homocysteine sulfur: cysteine metabolism to taurine and inorganic sulfur. J. Inherit. Metab. Dis. 34:17-32. https://doi.org/10.1007/ s10545-009-9006-9.

Swanson, K. S., N. R. Merchen, J. W. Erdman Jr., J. K. Drackley, F. Orias, G. N. Douglas, and J. C. Huhn. 2000. Technical note: A technique for multiple liver biopsies in neonatal calves. J. Anim. Sci. 78:2459-2463.

Symonds, M. E., S. P. Sebert, and H. Budge. 2010. Nutritional regulation of fetal growth and implications for productive life in ruminants. Animal 4:1075-1083. https://doi.org/10.1017/ S1751731110000479.

Szegedi, S. S., C. C. Castro, M. Koutmos, and T. A. Garrow. 2008. Betaine-homocysteine S-methyltransferase-2 is an S-methylmethionine-homocysteine methyltransferase. J. Biol. Chem. 283:8939 8945. https://doi.org/10.1074/jbc.M710449200.

Tomasi, M. L., T. W. Li, M. Li, J. M. Mato, and S. C. Lu. 2012. Inhibition of human methionine adenosyltransferase 1A transcription by coding region methylation. J. Cell. Physiol. 227:1583-1591. https://doi.org/10.1002/jcp.22875.

Ulrey, C. L., L. Liu, L. G. Andrews, and T. O. Tollefsbol. 2005. The impact of metabolism on DNA methylation. Hum. Mol. Genet. 14:R139-R147. https://doi.org/10.1093/hmg/ddi100.

Wang, L., L. Chen, Y. Tan, J. Wei, Y. Chang, T. Jin, and H. Zhu. 2013. Betaine supplement alleviates hepatic triglyceride accumulation of apolipoprotein $\mathrm{E}$ deficient mice via reducing methylation of peroxisomal proliferator-activated receptor alpha promoter. Lipids Health Dis. 12:34.https://doi.org/10.1186/1476-511X-12-34.

Wang, L. J., H. W. Zhang, J. Y. Zhou, Y. Liu, Y. Yang, X. L. Chen, C. H. Zhu, R. D. Zheng, W. H. Ling, and H. L. Zhu. 2014. Betaine attenuates hepatic steatosis by reducing methylation of the MTTP promoter and elevating genomic methylation in mice fed a highfat diet. J. Nutr. Biochem. 25:329-336. https://doi.org/10.1016/j. jnutbio.2013.11.007.

Wu, G., F. W. Bazer, T. A. Cudd, C. J. Meininger, and T. E. Spencer. 2004. Maternal nutrition and fetal development. J. Nutr. 134:2169-2172.

Wu, X., K. Huang, C. Wei, F. Chen, and C. Pan. 2010. Regulation of cellular glutathione peroxidase by different forms and concentrations of selenium in primary cultured bovine hepatocytes. J. Nutr. Biochem. 21:153-161. https://doi.org/10.1016/j. jnutbio.2008.12.006.

Xue, G. P., and A. M. Snoswell. 1986. Developmental changes in the activities of enzymes related to methyl group metabolism in sheep tissues. Comp. Biochem. Physiol. B 83:115-120.

Xue, G. P., A. M. Snoswell, and R. C. Fishlock. 1989. Partial purification and properties of the isozymes of S-adenosylmethionine synthetase from sheep liver. Biochem. Int. 18:525-535.

Zanker, I. A., H. M. Hammon, and J. W. Blum. 2000. Plasma amino acid pattern during the first month of life in calves fed the first colostrum at $0-2 \mathrm{~h}$ or at $24-25 \mathrm{~h}$ after birth. J. Vet. Med. A Physiol. Pathol. Clin. Med. 47:107-121.

Zhou, Z., T. A. Garrow, X. Dong, D. N. Luchini, and J. J. Loor. 2017. Hepatic activity and transcription of betaine-homocysteine methyltransferase, methionine synthase, and cystathionine synthase in periparturient dairy cows are altered to different extents by supply of methionine and choline. J. Nutr. 147:11-19. http://dx.doi.org/ https://doi.org/10.3945/jn.116.240234.

Zhou, Z., J. J. Loor, F. Piccioli-Cappelli, F. Librandi, G. E. Lobley, and E. Trevisi. 2016. Circulating amino acids in blood plasma during the peripartal period in dairy cows with different liver functionality index. J. Dairy Sci. 99:2257-2267. http://dx.doi.org/ https://doi.org/10.3168/jds.2015-9805. 